taking their cameras. People living in the vicinity reported that June $21 \mathrm{st}, 1980$ was the anniversary of the death of a nun who had suffered a heart-attack nearby. After the first few days no further sightings were reported.

St Thomas's Hospital,

Anne Cremona-Barbaro London SEI

\section{IDENTICAL TRIPLETS: NON-IDENTICAL PSYCHOSIS?}

DEAR SIR,

I have managed to subscribe to the Journal from this year for our hospital and I am able to make good use of it in postgraduate training.

May I comment on the article entitled: "Identical Triplets: Non-Identical Psychoses?" in the January issue $(140,1-6)$. In my opinion, the genetical conclusions that follow from the article may be too hasty. Despite the carefully considered diagnosis by a number of specialists, it does not appear entirely beyond doubt that the triplets had different forms of illness. It will be recalled that two of the triplets were schizophrenics, more precisely, their illness was diagnosed as schizoaffective psychosis and the third as manic-depressive psychosis. As a practising psychiatrist, I was bothered by the fact that an earlier schizoaffective episode had been recorded in the manic patient. However, one of the three persons examining the patients also diagnosed another patient (referred to in the article as $\mathbf{M}$ ) as a manicdepressive. After reading the brief histories of illness, I consider that there is a possibility that all three of the patients may be suffering from schizoaffective psychosis.

I considered it important to mention the above, since the danger could arise not only of losing the possibility of making finer distinctions within schizophrenia, but also of blurring even the Kraepelin dichotomy. The article thus leads to a fundamental problem and was therefore highly thought-provoking.

ANDRÁs KELEMEN

Fejér County Council Central Hospital and Clinic, 8000 Székesfehérvar, Seregélyesi ut 3, Hungarý
DeAR SIR,

We do not disagree with Dr Keleman that all 3 of the triplets may have "schizo-affective psychosis", in that they seem to have a form of illness which cannot be readily classified as either dementia praecox or manic depressive insanity in the classical Kraepelian sense. They are definitely genetically identical and it therefore seems inescapable that they all have the same illness despite certain dissimilarities at the clinical/phenotypic level.

We reported them to illustrate that in some instances the Kraepelian paradigm is inadequate and that patterns of psychopathology or course of illness do not infallibly reflect underlying genetic or biological substrate. We concluded in our paper that it is probable that "the area between Kraepelin's two entities is not unoccupied territory", but far from wishing to blur the distinctions within the Kraepelin system, as Dr Keleman fears, we are greatly in favour of refining present nosological systems. However, we believe that progress in this field is more likely to occur if attention is paid to biological correlates and to familial aggregation of particular symptom clusters. We have no axe to grind either in favour of the notion of a continuum of psychoses, with typical schizophrenia at one end and typical manic depressive illness at the other, or in favour of the separate existence of a third entity. However, we do consider that if psychiatric nosology is to avoid becoming a degenerate science (Urbach, 1974), then apparently anomalous cases such as the ' $Z$ ' triplets compel a fundamental re-examination of classificatory systems, rather than ad hoc adaptions of the existing orthodox schema.

Peter McGuffin

ADRIANNE REVELEY

Institute of Psychiatry,

De Crespigny Park,

London SE5 8AF

\section{Reference}

Urbach, P. (1974) Progress and degeneration in the "I.Q. debate". British Journal of Philosophy of Science, 25, 99-135. 